\title{
A Novel Five-level Optimized Carrier Multilevel PWM Quad-Inverter Six-Phase AC Drive
}

\author{
P.Sanjeevikumar ${ }^{1,}$, Frede Blaabjerg ${ }^{2}$, Patrick Wheeler $^{3}$, Viliam Fedák ${ }^{4}$, Mario J. Duran ${ }^{5}$, Pierluigi Siano ${ }^{5}$ \\ ${ }^{1}$ Department of Electrical \& Electronics Engineering, University of Johannesburg, Auckland Park, South Africa. \\ ${ }^{2}$ Center for Reliable Power Electronics (CORPE), Department of Energy Technology, Aalborg University, Aalborg, Denmark. \\ ${ }^{3}$ Institute for Aerospace Technology \& Power Electronics, Machines and Control (PEMC) Group, Department of Electrical \& Electronics \\ Engineering, Nottingham University, United Kingdom. \\ ${ }^{4}$ Department of Electrical Engineering \& Mechatronics, Technical University of Košice, Slovak Republic. \\ ${ }^{5}$ Department of Electrical Engineering, University of Málaga, Málaga, Spain. \\ ${ }^{6}$ Department of Industrial Engineering, University of Salerno, Campus of Fisciano, Salerno, Italy. \\ *Corresponding Author Email: sanjeevi_12@yahoo.co.in
}

\begin{abstract}
A novel single carrier pulse-width modulation (PWM) for a new quad-inverter configuration for multilevel sixphase asymmetrical open-winding ac converter is proposed in this article. Modularity of the circuit consist of four standard twolevel voltage source inverters (VSI) with slight modifications, i.e. one additional bi-direction switch (MOSFET/IGBT) in each phase and a link to neutral with two capacitors to generate increased output levels. Furthermore, original optimal single carrier zero-shifted five-level modulation (SCZSFM) algorithm is developed for each VSI to behave as equivalent to ones, a classical five-level multilevel inverter. Moreover, feasibility of the topology allows the VSIs to provide multilevel output voltage regardless of the open-winding electrical machine configuration. Also, the developed single carrier based PWM presents a straightforward solution compared to space vector modulation approaches for real time implementation. The total electric power shared among the four de buses and quadruples the power capability of VSIs. Complete ac drive modules are developed numerically using simulation in MATLAB/PLECS software. Observed set of results are depicted in this paper under balanced conditions to show the effectiveness of the proposal in good agreement with theoretical background. This proposal suits the need of low-voltage/high-
\end{abstract}

current applications to ac tractions, electrical vehicles and 'MoreElectric Aircraft' propulsion systems.

Keywords-Dual three-phase inverter, quad-inverter, sixphase inverter, multilevel inverters, multiphase drives, asymmetrical inverters, multiple space vectors, pulse-width modulation.

\section{INTRODUCTION}

AC drives are the renowned solutions for many electric applications for low, medium, and high power propulsion systems [1-2]. Viability of ac drives are remarkably improved by the invention of multilevel inverters [3]. High voltages are synthesized by multiple dc sources and multiple switching devices, solutions to high power applications. Also, benefitted with total harmonic distortion (THD) reduction and limited $\mathrm{dv} / \mathrm{dt}$ effects on output voltages and configured by voltage/current low-rating devices [3-5]. Many issues are still not clearly overcome with multilevel inverters vulnerability to potential failures. Mostly suffers with power parts and survey reveals $31-37 \%$ of faults is occurred by power parts with IGBT

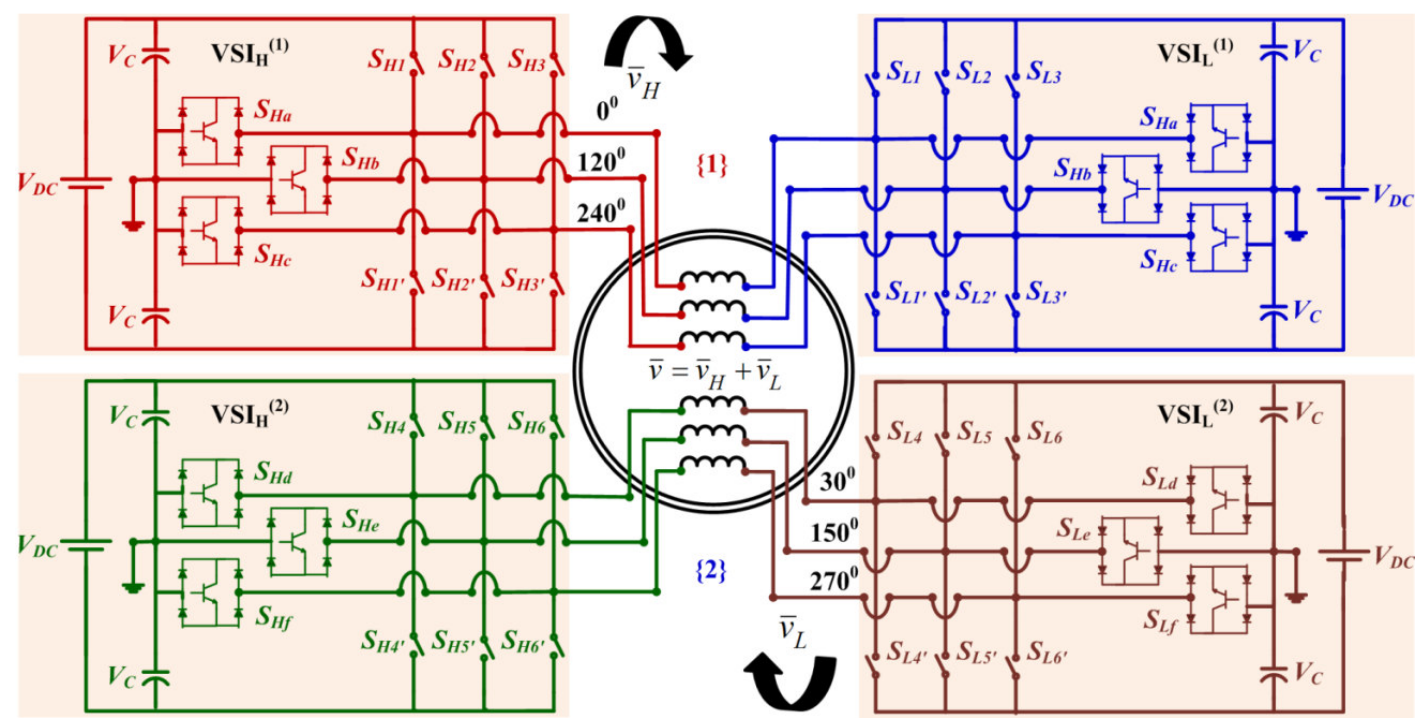

Fig. 1. Topology of quad-inverter five-level output six-phase asymmetrical open-winding converter for low-voltage and high-current applications with isolated four dc sources. 
devices and also due to capacitors and gate control methods [1, 6-8]. On the other hand, the technology development in multiphase ac drives make them candidates to replace standard three-phase drives in configurations with limited rating (MOSFET/IGBT) devices [9-19]. Many topologies are addressed for multiphase versions, but dual three-phase (sixphase) drives have shown good reliability, redundant structure, limited dc link ripples, high power density, and fault tolerant capabilities [13-17]. Usually configured by two adjacent phases spatially shifted by 600 (symmetrical type) [9, 13] or by 300 (asymmetrical one) [14-17] on applications. Advantages include easy splitting the phases as two standard sets of threephases driven by multiple classical VSIs as multiphase converter [14-18]. Generally, addressed with terminology as dual-, triple- and quadruple three-phase ac drives are applicable to low-voltage/high-current ac traction, electric vehicles and 'More-Electric Aircraft' propulsion systems (MEA) [18-19]. Specifically for the MEA, six-phase ac drives are suited as replacement for conventional hydraulic/pneumatic actuators, results in increased reliability under fault conditions and overall aeronautic propulsion improved [20-21]. Moreover, multiphase ac drives perform motoring/generator action during start and flight mode. It is evident that the grouping multi-phase and multi-level inverter could be effective to obtain the high power ratings configurations with limited voltage/current semiconductor devices [14-18, 22-30].

Classical VSIs are still remaining reliable, easy to configure as multi-phase and as well as multilevel converter by proper arrangement of VSIs [1-7, 14-18, 31-33]. In such cases, the conventional three-phase dual inverters are the good solution. The two three-phase VSIs (two-level) are connected each at the open-ends of windings [14-17, 31-33]. Moreover, the potential difference between two single inverter's leg potential constitutes the output voltages. Advantages of this arrangement include halved switching frequency and dc bus ratings. Moreover, two different sources with different potential can be incorporated to have constant output phase voltages (photovoltaic/fuel-cell). Also, the benefits are compromised to classical MLI's. Output qualities are assured in additional by common-mode currents cancellation are carried out by the PWM techniques or by deliberately kept isolated dc sources [13-17, 31-33]. Dual inverter with z-source impedance network in the dc link side configured and addressed for buck/boost the output voltages [31] with limited common-mode components and for grid integration with/without isolation transformer [32]. In this case again the dual inverters restricted with output levels, each leg pairs of phases by two VSI limit to three-level, and practically not possible to overcome. Investigations are relatively focused out to dual inverters for increasing the output levels to four-, five-, nine- times value and etc., obtained by increasing numer of the switches per phase or simply cascading multiple VSIs [25-26]. But for implementation it remains a complex configuration since it is bulky and it has limited reliability and redundancy. Modulations are adapted with complex space vector modulation (SVM) or multiple carrier based PWM techniques [25-28]. Recent investigations are focused on the four-level dual inverter configuration with classical modulation of phase disposition (PD) and/or alternative phase-opposition disposition (APOD) techniques [29]. But, the PWM modulation requires number of carrier is three, moreover the drive suffers if open-winding collapses to generate multilevel (four-level) output.

Considering above facts and motivated with commercial classical VSIs becoming more integrated, reliable, and easy-toreconfigured to higher number of phases this article proposes optimal single carrier zero-shifted five-level modulation (SCZSFM) algorithm for a modified quad-inverter six-phase asymmetrical open-end windings converter as shown in Fig. 1 $[14-17,33]$. The structure suits for medium power (lowvoltage/high-current) applications of ac tractions, electrical vehicle and MEA propulsion systems. Proposed single carrier modulation algorithm (independent modulation) has the capability to use each VSI as a standard five-level MLI's [33]. Modular power converter consists of four standard two-level VSIs and additionally each phase of VSIs as one bi-directional (IGBT) switch and links the neutral through two capacitor. Each VSI are connected across the open-end windings to frame six-phase multilevel converter [13]. Conformity of zerosequence components is null, since all four dc source are isolated by construction [14-17, 22-24, 33]. Additional future provided by the investigation is that each VSI generates fivelevel line-to-line outputs irrespective of open-winding and/or star-winding configuration. Total electric power capabilities are quadrupling and shares among the four isolated dc sources VSIs ( $\mathrm{H}$ and L). Reliability is assured under drive faulty conditions when one or two or three VSIs fail and propagate with minimum with single healthy VSI but with reduced dcrated power. To verify the effectiveness of the proposal, the complete ac drive system is developed numerically and tested with MATLAB/PLECS simulation software's under balanced conditions. A comprehensive set of observed results are depicted in the article to show the capabilities of converter to generate proper five-level outputs and sinusoidal behaviours of modulation. Observed results shown close conformity by its performance with both the expectations and the agreement with developed theoretical background.

\section{Multiple AND SPlit-PHASE DECOMPOSITION SPACE VECTOR TRANSFORMATION}

\section{A. Multiple space vector transformation}

Multiphase space vectors are used to represent a six-phase asymmetrical system numerically in orthogonal sub-spaces as given below [9-10, 14-17]:

$$
\begin{gathered}
\bar{x}_{1}=\frac{1}{3}\left[x_{1}+x_{2} \alpha^{4}+x_{3} \alpha^{8}+x_{4} \alpha+x_{5} \alpha^{5}+x_{6} \alpha^{9}\right] \\
\bar{x}_{3}=\frac{1}{3}\left[\left(x_{1}+x_{2}+x_{3}\right)+j\left(x_{4}+x_{5}+x_{6}\right)\right] \\
\bar{x}_{5}=\frac{1}{3}\left[x_{1}+x_{2} \alpha^{8}+x_{3} \alpha^{4}+x_{4} \alpha^{5}+x_{5} \alpha+x_{6} \alpha^{9}\right]
\end{gathered}
$$

Where, rotating spatial displacement $\alpha=\exp (j \pi / 6)$, between two sets of three-phase windings [14-17]. The multiple space vectors $\bar{x}_{1}, \bar{x}_{3}$ and $\bar{x}_{5}$ are the sub-zones and exposed to $d_{1}-q_{1}$, $d_{3}-q_{3}$, and $d_{5}-q_{5}$ are orthogonal to each other respectively.

Now, to introduce split-phase decomposition space vectors, the six-phase system are splits into two three-phase sub- 
systems $\{1\}$ and $\{2\}$ and driven by four isolated dc source VSIs is given as below [22-24]:

$$
\begin{aligned}
& \{1\} \rightarrow\left\{x_{1}^{(1)}=x_{1} ; x_{2}^{(1)}=x_{2} ; x_{3}^{(1)}=x_{3},\right. \\
& \{2\} \rightarrow\left\{x_{1}^{(2)}=x_{4} ; x_{2}^{(2)}=x_{5} ; x_{3}^{(2)}=x_{6}\right.
\end{aligned} .
$$

The arbitrary rotating space vectors are $\bar{x}^{(1)}, \bar{x}^{(2)}$ and the zerosequence components are $x_{0}^{(1)}, x_{0}^{(2)}$ defined for two threephase sub-system $\{1\}$ and $\{2\}$ as given below:

$$
\begin{aligned}
& \{1\} \rightarrow\left\{\begin{array}{l}
\bar{x}^{(1)}=\frac{2}{3}\left[x_{1}^{(1)}+x_{2}^{(1)} \alpha^{4}+x_{3}^{(1)} \alpha^{8}\right] \\
x_{0}^{(1)}=\frac{1}{3}\left[x_{1}^{(1)}+x_{2}^{(1)}+x_{3}^{(1)}\right]
\end{array}\right. \\
& \{2\} \rightarrow\left\{\begin{array}{l}
\bar{x}^{(2)}=\frac{2}{3}\left[x_{1}^{(2)}+x_{2}^{(2)} \alpha^{4}+x_{3}^{(2)} \alpha^{8}\right] \\
x_{0}^{(2)}=\frac{1}{3}\left[x_{1}^{(2)}+x_{2}^{(2)}+x_{3}^{(2)}\right]
\end{array}\right.
\end{aligned}
$$

By introducing Eq. 2 and Eq. 3, in Eq. 1, the multiple space vectors and split-phase space vectors are related as:

$$
\begin{aligned}
& \left\{\begin{array}{l}
\bar{x}_{1}=\frac{1}{2}\left[\bar{x}^{(1)}+\alpha \bar{x}^{(2)}\right] ; \bar{x}_{5}^{*}=\frac{1}{2}\left[\bar{x}^{(1)}-\alpha \bar{x}^{(2)}\right] . \\
\bar{x}_{3}=x_{0}^{(1)}+j x_{0}^{(2)}
\end{array}\right. \\
& \bar{x}^{(1)}=\bar{x}_{1}+\bar{x}_{5}^{*} ; x_{0}^{(1)}=\bar{x}_{3} \cdot 1 ; \bar{x}^{(2)}=\alpha^{-1}\left(\bar{x}_{1}-\bar{x}_{5}^{*}\right) ; \\
& x_{0}^{(2)}=\bar{x}_{3} \cdot j
\end{aligned}
$$

The operational symbols “*” and "."denote mathematical complex conjugate and scalar (dot) product respectively.

\section{Single CARrier ZERO-SHIFTEd Modulation (SCZSFM) ALGORITHM}

The sum of power of VSIs constitute the total electric power $P$ of the dual three-phase (six-phase) windings $\{1\}$ and $\{2\}[14-17]$ and expressed as below:

$$
\begin{gathered}
P=P^{(1)}+P^{(2)}=\frac{3}{2} \bar{v}^{(1)} \cdot \bar{i}^{(1)}+\frac{3}{2} \bar{v}^{(2)} \cdot \bar{i}^{(2)} \\
P=P^{(1)}+P^{(2)}=\frac{3}{2}\left[\left(\bar{v}_{H}^{(1)}+\bar{v}_{L}^{(1)}\right) \cdot \bar{i}^{(1)}+\left(\bar{v}_{H}^{(2)}+\bar{v}_{L}^{(2)}\right) \cdot \bar{i}^{(2)}\right]
\end{gathered}
$$

For easy implementation for modulation schemes, the bidirectional switch per phase and two capacitors with neutral are neglected in the Fig. 1, circuit transferred to classical 2level VSIs. Modulating space vector for the output voltage vector $\bar{v}$ can be expressed as the sum of the voltage vectors $\bar{v}^{(1)}$ and $\bar{v}^{(2)}$ of the two three-phase windings $\{1\}$ and $\{2\}$ as:

$$
\bar{v}=\bar{v}^{(1)}+\bar{v}^{(2)}
$$

Again, by Eq. 7 considering Eq. 3 then the modulating vectors for first $\{1\}$ and second $\{2\}$ three-phase windings are expressed as below:

$$
\begin{gathered}
\bar{v}^{(1)}=\bar{v}_{H}^{(1)}+\bar{v}_{L}^{(1)} \\
\bar{v}^{(2)}=\bar{v}_{H}^{(2)}+\bar{v}_{L}^{(2)}
\end{gathered}
$$

By Eq. 4 and Eq. 8, the modulating vector for $\mathrm{VSI}_{\mathrm{H}}{ }^{(1)}$ and $\mathrm{VSI}_{\mathrm{L}}{ }^{(1)}$, now represented as below:

$$
\begin{aligned}
& \bar{v}_{H}^{(1)}=\frac{1}{3} V_{D C}\left(S_{H 1}+S_{H 2} e^{j 2 \pi / 3}+S_{H 3} e^{j 4 \pi / 3}\right) \\
& \bar{v}_{L}^{(1)}=-\frac{1}{3} V_{D C}\left(S_{L 1}+S_{L 2} e^{j 2 \pi / 3}+S_{L 3} e^{j 4 \pi / 3}\right)
\end{aligned}
$$

Therefore, the modulating vector for first three-phase winding $\{1\}$ represented as:

$$
\bar{v}^{(1)}=\frac{1}{3} V_{D C}\left(\begin{array}{l}
S_{H 1}+S_{H 2} e^{j 2 \pi / 3}+S_{H 3} e^{j 4 \pi / 3}- \\
S_{L 1}+S_{L 2} e^{j 2 \pi / 3}+S_{L 3} e^{j 4 \pi / 3}
\end{array}\right)
$$

Similar by Eq. 4 and Eq. 8, the modulating vector for $\operatorname{VSI}_{\mathrm{H}}{ }^{(2)}$ and $\mathrm{VSI}_{\mathrm{L}}{ }^{(2)}$, now expressed as below:

$$
\begin{aligned}
& \bar{v}_{H}^{(2)}=\frac{1}{3} V_{D C}\left(S_{H 4} \alpha+S_{H 5} \alpha e^{j 2 \pi / 3}+S_{H 6} \alpha e^{j 4 \pi / 3}\right) \\
& \bar{v}_{L}^{(2)}=-\frac{1}{3} V_{D C}\left(S_{L 4} \alpha+S_{L 5} \alpha e^{j 2 \pi / 3}+S_{L 6} \alpha e^{j 4 \pi / 3}\right)
\end{aligned}
$$

Therefore, the modulating vector for second three-phase winding $\{2\}$ represented as:

$\bar{v}^{(2)}=\frac{1}{3} V_{D C}\left(\begin{array}{l}S_{H 4} \alpha+S_{H 5} \alpha e^{j 2 \pi / 3}+S_{H 6} \alpha e^{j 4 \pi / 3}- \\ S_{L 4} \alpha+S_{L 5} \alpha e^{j 2 \pi / 3}+S_{L 6} \alpha e^{j 4 \pi / 3}\end{array}\right)$

By Eq. 11 and Eq. 13, introduced to Eq. 7 then the arbitrary modulating vector can be written as [22-23]:

$$
\begin{aligned}
\bar{v}= & \frac{1}{3} V_{D C}\left(\begin{array}{l}
S_{H 1}+S_{H 2} e^{j 2 \pi / 3}+S_{H 3} e^{j 4 \pi / 3}- \\
S_{L 1}+S_{L 2} e^{j 2 \pi / 3}+S_{L 3} e^{j 4 \pi / 3}
\end{array}\right)+ \\
& \frac{1}{3} V_{D C}\left(\begin{array}{l}
S_{H 4} \alpha+S_{H 5} \alpha e^{j 2 \pi / 3}+S_{H 6} \alpha e^{j 4 \pi / 3}- \\
S_{L 4} \alpha+S_{L 5} \alpha e^{j 2 \pi / 3}+S_{L 6} \alpha e^{j 4 \pi / 3}
\end{array}\right)
\end{aligned}
$$

Where, noted switching states for upper-states are $\left\{S_{H}, S_{H 1}\right.$, $\left.S_{H 2}, S_{H 3} S_{H 4}, S_{H 5}, S_{H 6}\right\}=\{1\}$, and for lower-states $\left\{S_{L}, S_{L 1}, S_{L 2}\right.$, $\left.S_{L 3}, S_{L 4}, S_{L 5}, S_{L 6}\right\}=\{0\}$ of $\operatorname{VSI}_{\mathrm{H}}{ }^{(1)}$ and $\mathrm{VSI}_{\mathrm{L}}{ }^{(1)}$. Moreover, the zero-sequence components are null if considered all are balanced conditions. Now, Eq. 14 rewritten as four separate three-phase VSI as Eq. 10 and Eq. 12. The optimal single carrier zero shifted five-level modulation (SCZSFM) algorithm for the quad-inverter six-phase converter is shown in Fig. 2 and Fig. 3 [32-35]. The modulating reference signals (aero-shifted) are compared against standard single triangular carrier and to utilization the dc buses maximum with proper five-level multilevel outputs. In detail, Fig. 2(A) depicts the single carrier zero-shifted five-level modulation (SCZSFM) algorithm of phase ' $\mathrm{a}$ ' of $\mathrm{VSI}_{\mathrm{H}}{ }^{(1)}$, the same applies to other phases VSI (H and L). Fig. 2(B) depicts the detailed zero- 


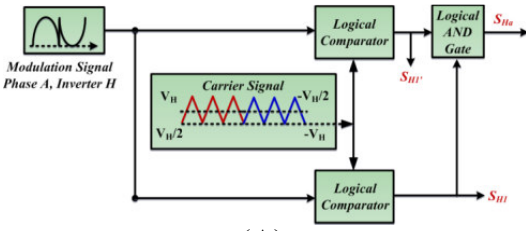

(A)

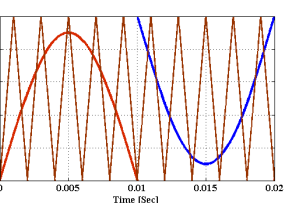

(B)
Fig. 2. Proposed modulation algorithm. (A) Multilevel PWM scheme with one carrier for phase ' $\mathrm{a}$ ' of inverter $\mathrm{VSI}_{\mathrm{H}}{ }^{(1)}$. (B) Reference zero shifted modulating signal and carrier signal at $500 \mathrm{~Hz}$ reduced display for better visibility (red reference: $S_{H I}$ and blue reference: $S_{H I}$ ).
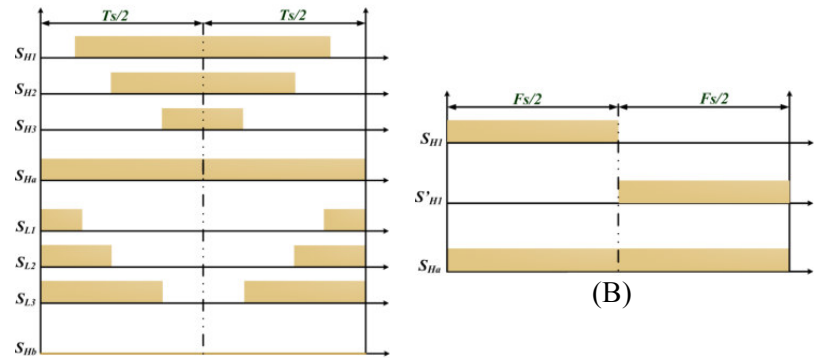

(A)

Fig. 3. Illustration of proposed multilevel carrier PWM algorithm. (A). Modulation scheme for $\mathrm{VSI}_{\mathrm{H}}{ }^{(1)}$ and $\mathrm{VSI}_{\mathrm{L}}{ }^{(1)}$. (B) Single leg (phase 'a') modulation pattern for $\mathrm{VSI}_{\mathrm{H}}{ }^{(1)}$. Modulation index $=0.8$.

shifted reference signal for switch $S_{H 1}$, (red) and $S_{H 1}^{\prime}$, (blue), where carrier signal are presented with low frequency for clear resolution and visibility. For phase ' $\mathrm{a}$ ' $\mathrm{VSI}_{\mathrm{H}}{ }^{(1)}$, the bidirectional switch $S_{H a}$ modulates throughout the fundamental period and provides additional level to the converter, i.e. always swap $\{1,0\}$. The upper-state device $S_{H 1}$ will modulate only in the first half-cycle ON-state and second half cycle retains OFF-state of the complete fundamental period, While, lower-state device $S_{H I}$ will modulated in vice-versa to the upper-state device $S_{H l}$. Particularly the single carriers modulation are carried out with zero-shifted, and ensure $+V_{H} / 2$, and $+V_{H}$ generated by the device $S_{H I}$, whereas $-V_{H} / 2$, and $-V_{H}$ are generated by $S_{H I}^{\prime}$. Introduction of the bidirectional switch to the power converter generates additional levels $0 V_{H}$ to $V_{H} / 2$ to provide zero levels and $+/-V_{H} / 2$ levels to devices $S_{H 1}$, and $S_{H 1}^{\prime}$ Correspondingly switching pattern for $\mathrm{VSI}_{\mathrm{H}}{ }^{(1)}$, and $\mathrm{VSI}_{\mathrm{L}}{ }^{(1)}$ are depicted in Fig. 3(A), clearly showing phase opposition in modulation for vector addition of outputs. Fig. 3(B) illustrates the single-leg modulation for phase 'a' of $\mathrm{VSI}_{\mathrm{H}}{ }^{(1)}$. Extension can be performed with the power sharing regulation in symmetrical /asymmetrical conditions can be performed between the four dc sources of the inverters $\mathrm{H}$ and L.

\section{NumERICAL SimULATION RESUltS AND DiscusSiON}

For the investigation purposes the complete ac converter drive is numerically modeled using MATLAB/PLECS simulation software's and tested. Detailed main parameters are taken from Table I under balanced condition keeping modulation index of $\mathrm{VSI}_{\mathrm{H}}{ }^{(1)}, \mathrm{VSI}_{\mathrm{L}}{ }^{(1)}, \mathrm{VSI}_{\mathrm{H}}{ }^{(2)}, \mathrm{VSI}_{\mathrm{L}}{ }^{(2)}$ to 0.8 for verify the effectiveness of proposal. Fig. 4 and Fig. 5 describe the observed performance results of the quad-inverter sixphase ac converter for its multilevel generation capabilities.
TABle I. Main Parameters of SiX-Phase MultileVel Converter.

\begin{tabular}{ll|l}
\hline Dc Bus & $V_{D C}$ & $=200 \mathrm{Volts}$ \\
\hline Load Resistances & $R$ & $=8 \Omega$ \\
\hline Load Inductances & $L$ & $=10 \mathrm{mH}$ \\
\hline Fundamental Frequency & $F$ & $=50 \mathrm{~Hz}$ \\
\hline Switching Frequency & $F_{S}$ & $=5 \mathrm{KHz}$ \\
\hline Capacitors & $V_{C}$ & $=2200 \mu \mathrm{F}$ \\
\hline
\end{tabular}

Fig. 4(A), Fig. 4(B) and Fig. 4(I), Fig. 4(J) illustrates the observed line-to-line voltages of $\mathrm{VSI}_{\mathrm{H}}{ }^{(1)}, \mathrm{VSI}_{\mathrm{L}}{ }^{(1)}$ and $\mathrm{VSI}_{\mathrm{H}}{ }^{(2)}$, $\mathrm{VSI}_{\mathrm{L}}{ }^{(2)}$, along with time scale averaged its fundamental components. It is confirmed that the generated voltages are of proper five-level outputs and shown performance equivalent to classical MLI's. Also, it is noticed that $\mathrm{VSI}_{\mathrm{H}}$ and $\mathrm{VSI}_{\mathrm{L}}$ are out of phase with respect to each other. Also, spatial displacement of $30^{\circ}$ degree is clearly visible between the two three-phase open-windings $\left(\operatorname{VSI}_{\mathrm{H}}^{(1)}, \mathrm{VSI}_{\mathrm{L}}^{(1)}\right)\{1\}$ and $\left(\mathrm{VSI}_{\mathrm{H}}^{(2)}, \mathrm{VSI}_{\mathrm{L}}^{(2)}\right)\{2\}$. Furthermore, it is confirmed by the fundamental components of VSIs that they are equal in amplitude and shown balanced operation as expected. Hence, it is proved that each VSI are capable of generating optimal five-level outputs by the developed single carrier zero-shifted five-level modulation (SCZSFM) algorithm and overcomes the drawback set by previously addressed dual inverter configurations [14-17, 2232].

Fig. 4(C), Fig. 4(D) and Fig. (K), Fig. 4(L) are the fictitiously measured phase voltage of $\operatorname{VSI}_{\mathrm{H}}{ }^{(1)}, \mathrm{VSI}_{\mathrm{L}}{ }^{(1)}$, and $\mathrm{VSI}_{\mathrm{H}}{ }^{(2)}, \mathrm{VSI}_{\mathrm{L}}{ }^{(2)}$ with time scale averaged its fundamental components of first and second three-phase windings $\{1\}$ and $\{2\}$. Again, by the observed results it could be confirmed that $\mathrm{VSI}_{\mathrm{H}}$ and $\mathrm{VSI}_{\mathrm{L}}$ generated proper 9-level outputs, which is expected. Generated fundamental components of $\mathrm{VSI}_{\mathrm{H}}{ }^{(1)}, \mathrm{VSI}_{\mathrm{L}}{ }^{(1)}$ are in agreement to Eq. 10 and also they are out of phase with each other. Similarly, the fundamental components of $\mathrm{VSI}_{\mathrm{H}}{ }^{(2)}, \mathrm{VSI}_{\mathrm{L}}{ }^{(2)}$ are in agreement to Eq. 12 and also here they are out of phase with each other, which is to be and expected for both openwindings $\{1\}$ and $\{2]$. Moreover, it is clearly visible that the fundamental components of the phase voltages are of same amplitudes and confirms the balanced operation keeping modulation index of VSIs $=0.8$. Fig. 4(E) and Fig. 4(M) depicts the open-end windings phase voltages generated by the first-phase ' $a$ ' of first three-phase $\{1\}$ and the second threephase open-windings $\{1\}$ and $\{2\}$, along with time scale averaged its fundamental components. Firstly, it is confirmed that the voltage generated are 9-levels in both open-windings and amplitudes are obtained by the vector addition of phase voltages of $\mathrm{VSI}_{\mathrm{H}}{ }^{(1)}, \mathrm{VSI}_{\mathrm{L}}{ }^{(1)}$ for Fig. 4(E) and $\mathrm{VSI}_{\mathrm{H}}{ }^{(2)}, \mathrm{VSI}_{\mathrm{L}}{ }^{(2)}$ for Fig. 4(M), which is actually an expected outcome. As expected, the phase voltages are equal in amplitude to confirm again the balanced operation. Furthermore, observed the arbitrarily phase sifted by $30^{\circ}$ between phase voltages of two three-phase windings $\{1\}$ and $\{2\}$. Correspondingly, two three-phase currents of six-phase open-windings $\{1\}$ and $\{2\}$ are shown by Fig. 4(F) and Fig. 4(N). It could confirm that amplitude of currents is equal by its amplitude and shown sinusoidal behavior by nature. Hence, it is shown that quad-inverters are modulated sinusoidally by the developed SCZSFM PWM algorithm. Also, it is noticed a spatial displacement of $30^{\circ}$ between first three-phase $\{1\}$ and second three-phase $\{2\}$ 


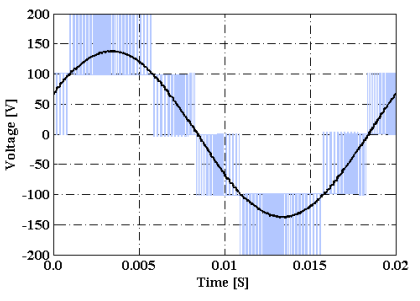

(A). Line-to-line voltage generated by $\operatorname{VSI}_{\mathbf{H}}{ }^{(1)}$.

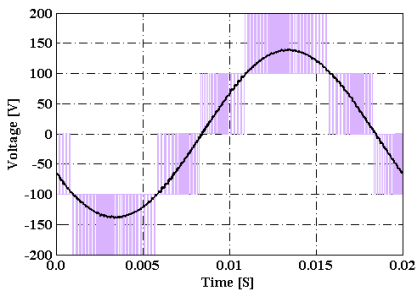

(B). Line-to-line voltage generated by VSI $_{L}{ }^{(1)}$.

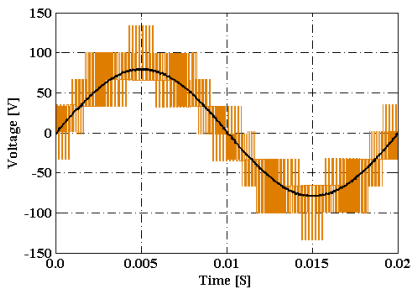

(C). Fictitiously measured first-phase voltage of $\mathbf{V S I}_{\mathbf{H}}{ }^{(1)}$

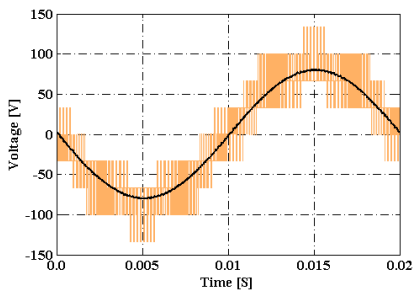

(D). Fictitiously measured first-phase voltage of $\mathbf{V S I}_{\mathbf{L}}{ }^{(1)}$

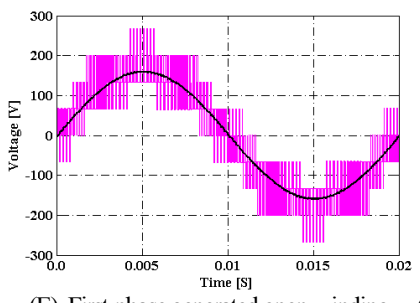

(E). First-phase generated open-winding

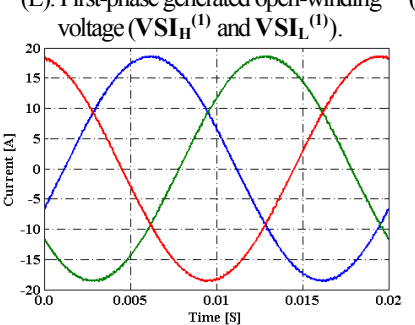

(F). First three-phase generated openwinding currents $\left(\mathbf{V S I}_{\mathbf{H}}{ }^{(1)}\right.$ and $\left.\mathbf{V S I}_{\mathbf{L}}{ }^{(\mathbf{1})}\right)$.

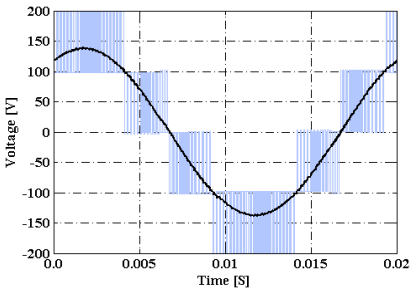

(I). Line-to-line voltage generated by $\mathbf{V S I}_{\mathbf{H}}{ }^{(2)}$.

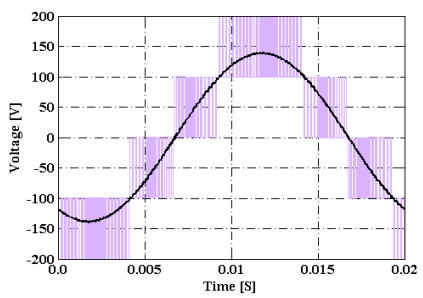

(J). Line-to-line voltage generated by $\mathbf{V S I}_{\mathbf{L}}{ }^{(2)}$.

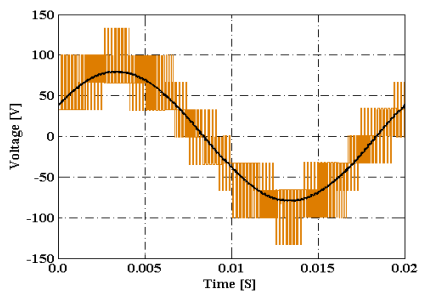

(K). Fictitiously measured first-phase voltage of $\mathbf{V S I}_{\mathbf{H}}{ }^{(2)}$.

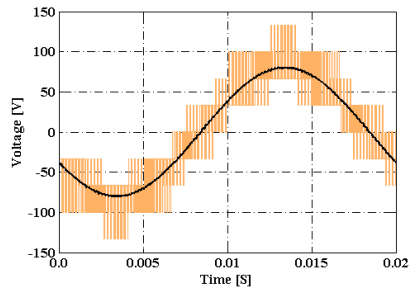

(L). Fictitiously measured first-phase voltage of $\mathrm{VSI}_{\mathbf{L}}{ }^{(2)}$.

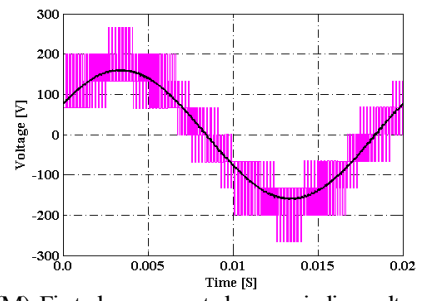

(M). First-phase generated open-winding voltage

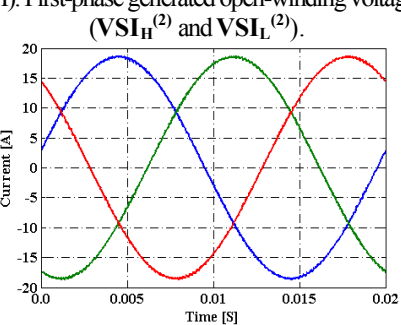

(N). Second three-phase generated openwinding currents $\left(\mathbf{V S I}_{\mathbf{H}}{ }^{(2)}\right.$ and $\left.\mathbf{V S I}_{\mathbf{L}}{ }^{(2)}\right)$.

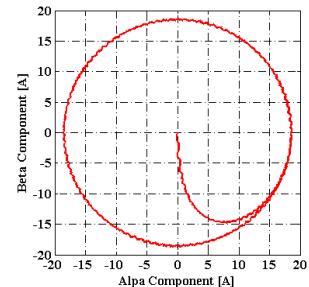

(G). First three-phase currents trajectories in first $\left(d_{l}-q_{l}\right)$ sub-spaces rotating $\alpha-\beta$ planes.

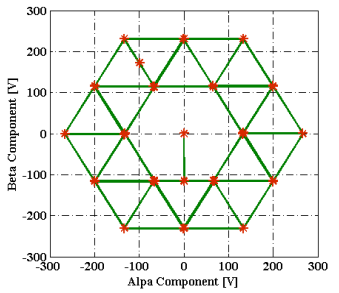

(H). Trajectory of first three-phase voltages in $d_{1}-q_{1}$ sub-space rotating $\alpha-\beta$ planes.

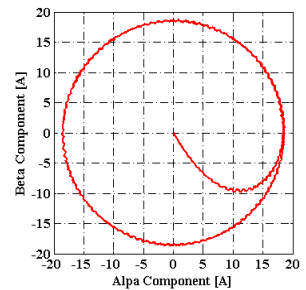

$(\mathrm{O})$. Second three-phase currents trajectories in first $\left(d_{1}-q_{1}\right)$ sub-spaces rotating $\alpha-\beta$ planes.

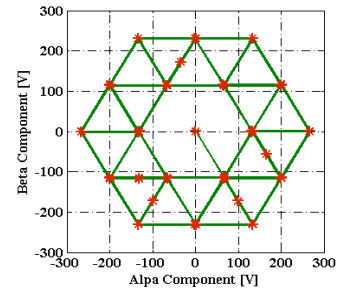

(P). Trajectory of second three-phase voltages in $d_{l}-q_{l}$ sub-space rotating $\alpha-\beta$ planes.
Fig. 4. Response of numerical simulation development of the proposed single carrier based multilevel quad-inverter asymmetrical six-phase multilevel converter. Balanced operation modulation index of $\mathrm{VSI}_{\mathrm{H}}{ }^{(1)}, \mathrm{VSI}_{\mathrm{L}}{ }^{(1)}, \mathrm{VSI}_{\mathrm{H}}{ }^{(2)}$, $\mathrm{VSI}_{\mathrm{L}}^{(2)}$ kept 0.8 . Voltages are depicted with time averaged fundamental components.

windings currents, which is actually predicted ones. Therefore, the total power among the four isolated dc sources are shared equally for quadruples the capability of singe VSI.

To show the effectiveness, trajectories of the two threephase currents are projected in alpha-beta $(\alpha-\beta)$ rotating planes of first sub-space $\left(d_{1}-q_{1}\right)$ as given by Fig. $4(\mathrm{G})$ and Fig. $4(\mathrm{O})$. When the total electric power is equally shared among $\operatorname{VSI}_{\mathrm{H}}{ }^{(1)}$, $\mathrm{VSI}_{\mathrm{L}}{ }^{(1)}, \mathrm{VSI}_{\mathrm{H}}{ }^{(2)}$, and $\mathrm{VSI}_{\mathrm{L}}{ }^{(2)}$, the rotating components revolves along a circular trajectory (at constant frequency) and it is verified by depicted results. Similarly, Fig. 4(H) and Fig. 4(P) are the trajectories of two three-phase voltages of open-wind windings $\{1\}$ and $\{2\}$. It is can be easily confirmed by the developed trajectories that each VSI are modulated in proper 3-levels and additional levels are generated by the bidirectional switches, by the adapted SCZSFM PWM techniques. Finally, the depicted results confirm the satisfactory performances by the proposed five-level quadinverter configuration for six-phase asymmetrical ac converter and shown good agreement with the theoretical developments.

\section{CONCLUSION}

This article proposes an optimal single carrier zero-shifted five-level modulation scheme for modified quad-inverter sixphase asymmetrical converter. The power converter circuit is derived and reconfigured from four standard two-level voltage source inverters with slight modifications. In particular each phase contains one additional bi-direction switch and links the neutral through two capacitors. Also, the developed SCZSFM PWM algorithm capable to generating each VSI as equivalent to ones classical five-level multilevel inverters. Set of confirmatory results are presented by numerical modeling and shown that the lower order harmonics are suppressed in the outputs. Moreover, the total power is quadruples between four 
isolated dc sources in the balanced power operations. Quadinverter configuration is reliable under circumstances of asymmetrical available dc sources.

\section{ACKNOWLEDGMENT}

This work was supported by the Scientific Grant Agency of the Slovak Republic under the Contract no. VEGA 1/0464/15.

\section{REFERENCES}

[1] Frede Blaabjerg, M.M.Pecht, "Robust Design and Reliability of Power Electronics," IEEE Trans. on Power Electron., vol. 30, no. 5, pp. 23732374, 2015.

[2] A.L. Julian, G. Oriti, "A comparison of redundant inverter topologies to improve voltage source inverter reliability," IEEE Trans. on Ind. Appl., vol. 43, pp. 1371-1378, 2007.

[3] L. G. Franquelo, J. Rodriguez, J. I. Leon, S. Kouro, R. Portillo and M. M. Prats, "The age of multilevel converters arrives," IEEE Ind. Electron. Magazine, vol. 2, no. 2, pp. 28-39, June 2008.

[4] J. Rodriguez, S. Bernet, Bin Wu, J.O. Pontt, S. Kouro, "Multilevel voltage-source-converter topologies for industrial medium-voltage drives,' IEEE Trans. Ind. Electron., vol. 54, no. 6, Dec 2007, pp. 2930-2945.

[5] J. Rodríguez, J.S. Lai, F. Zheng Peng, "Multilevel inverters: A survey of topologies, controls, and applications," IEEE Trans. on Industry Electronics, Vol. 49, no. 4, pp. 724-738, Aug. 2002.

[6] S. Yang, A. Bryant, P. Mawby, D. Xiang, Li Ran, P. Tavner, "An industry-based survey of reliability in power electronic converters," IEEE Trans. on Ind. Electron., vol. 47, no. 3, pp. 1441-1451, May-June 2011.

[7] S. Yang, D. Xiang, A. Bryant, P. Mawby, Li Ran, P. Tavner, "Condition monitoring for device reliability in power electronic converters: A review," IEEE Trans. on Power Electron., vol. 25, no. 11, pp. 2734-2752, Nov. 2010.

[8] H.A.H. Soliman, H.Wang, F.Blaabjerg, "A review of the condition monitoring of capacitors in power electronics converters," Conf. Proc. of IEEE Intl Electromotion Joint Conf., IEEE-ACEMP-OPTIM'15, Turkey, pp. 243-249, 2-4 Sept. 2015.

[9] G.K.Singh, "Multi-phase induction machine drive research-a survey," $J$. of Electric Power System Research, Elsevier Pub., vol. 62, pp. 139-147, 2002.

[10] E. Levi, "Advances in Converter Control and Innovative Exploitation of Additional Degrees of Freedom for Multiphase Machines," IEEE Trans. Ind. Electron., vol 63, no. 1, pp. 433-448, 2016.

[11] F. Barrero, M.J. Duran, "Recent Advances in the Design, Modeling and Control of Multiphase Machines - Part 1," IEEE Trans. Ind. Electron. vol 63, no. 1, pp. 449-458, 2016.

[12] M.J. Duran, F. Barrero, "Recent Advances in the Design, Modeling and Control of Multiphase Machines - Part 2," IEEE Trans. Ind. Electron., vol 63, no. 1, pp. 459-468, 2016.

[13] R.Bojoi, F.Farina, F.Profumo, A.Tenconi, "Dual three-phase induction machine drives control- A survey,"IEE J. Trans. on Ind. Appl., vol. 126, no. 4, 2006.

[14] P.Sanjeevikumar, G.Grandi, Frede Blaabjerg, Patrick W.Wheeler, Olorunfemi Ojo, "Analysis and Implementation of Power Management and Control Strategy for Six-Phase Multilevel AC Drive System in Fault Condition," Engg. Science and Tech; An Intl. J. (JESTECH), Elsevier Pub., 13 Jul. 2015. doi: 10.1016/j.jestch. 2015.07.007.

[15] P.Sanjeevikumar, G.Grandi, Frede Blaabjerg, Joseph Olorunfemi Ojo, Patrick W.Wheeler, "Power Sharing Algorithm for Vector Controlled Six-Phase AC Motor with Four Customary Three-Phase Voltage Source Inverter Drive,"Engg. Science and Tech; An Intl. J. (JESTECH), Elsevier Pub., vol. 16, no. 3, pp. 405-415, 11 Feb. 2015.

[16] G. Grandi, P. Sanjeevikumar, D. Ostojic, C. Rossi, "Quad-inverter configuration for multi-phase multi-level ac motor drives,"Conf. Proc. Intl. Conf. Computational Technologies in Elect. and Electron. Engg., IEEE-SIBIRCON'10, Irkutsk Listvyanka (Russia), pp. 631-638, 11-15 Jul. 2010.

[17] G. Grandi, P. Sanjeevikumar, Y. Gritli, F. Filippetti, "Fault-tolerant control strategies for quad-inverter induction motor drives with one failed inverter,"Conf. Proc. IEEE 20th Intl. Conf. on Electrical Machines, IEEE-ICEM'12, Marseille (France), pp. 957-964, 2-5 Sept. 2012.

[18] A.Tani, M.Mengoni, L. Zarri, G.Serra, D.Casadei, "Control of multiphase induction motors with an odd number of phases under open circuit
faults,'IEEE Trans. on Power Electronics, vol. 27, no. 2, pp. 565-577, 2012.

[19] F. Scuiller, J.F. Charpentier, E. Semail, "Multi-star multi-phase winding for a high power naval propulsion machine with low ripple torques and high fault tolerant ability," Proc. of Vehicle Power and Propulsion Conference, Lille, France, pp. 1-5, 1-3 Sept. 2010.

[20] W. Cao, B.C. Mecrow, G.J. Atkinson, J.W. Bennett, D.J. Atkinson, "Overview of electric motor technologies used for More-Electric Aircraft (MEA)," IEEE Trans. on Ind. Electron., vol. 59, no. 9, pp. 3523-3531, Sept. 2012.

[21] A. Cavagnino, Zijian Li, A. Tenconi, S. Vaschetto, "Integrated generator for More Electric Engine: design and testing of a scaled size prototype," IEEE Conf. Proc. of ECCE 2012, Raleigh, NC, USA, pp. 542-549, 15-20 Sept. 2012

[22] G. Grandi, P. Sanjeevikumar, D. Casadei, "Preliminary hardware implementation of a six-phase quad-inverter induction motor drive", Conf. Proc. The 14th European Conf. on Power Electron. and Appl., IEEE-EPE'11, Birmingham (United Kingdom), pp. 1-9, 30 Aug.-1 Sept 2011.

[23] G. Grandi, P. Sanjeevikumar, Y. Gritli, F. Filippetti, "Experimental investigation of fault-tolerant control strategies for quad-inverter converters," Conf. Proc. IEEE Intl. Conf. on Electrical System for Aircraft, Railway and Ship Propulsion, IEEE-ESARS'12, Bologna (Italy), pp. 1-8, 16-18 Oct. 2012.

[24] G. Grandi, P. Sanjeevikumar, D. Casadei, "Preliminary hardware implementation of a six-phase quad-inverter induction motor drive,"Conf. Proc. The 14th European Conf. on Power Electron. and Appl., IEEE-EPE'11, Birmingham (United Kingdom), pp. 1-9, 30 Aug.1 Sept. 2011

[25] B.V.Reddy, V.T.Somasekhar, Y.Kalyan, "Decoupled space-vector PWM strategies for a four-level asymmetrical open-end winding induction motor drive with waveform symmetries," IEEE Trans. Ind. Electron. vol. 58, no. 11, pp. 5130-5141, Nov. 2011.

[26] P.P.Rajeevan, K.Gopakumar, "A hybrid five-level inverter with common-mode voltage elimination having single voltage source for IM drive applications," IEEE Trans. on Ind. Appl., vol. 48, no. 6, pp. $2037-$ 2047, Nov. 2012.

[27] N.Bodo, E.Levi, M.Jones, "Investigation of carrier-based PWM techniques for a five-phase open-end winding drive topology," IEEE Trans. Ind. Electron., vol. 60, no. 5, pp. 2054-2065, May 2013.

[28] O.Dordevic, M.Jones, E.Levi, "A comparison of carrier-based and space vector PWM techniques for three-level five-phase voltage source inverters," IEEE Trans. Ind. Informat., vol. 9, no. 2, pp. 609-619, May 2013.

[29] M.Darijevic, M.Jones, E.Levi, “An Open-End Winding Four-Level FivePhase Drive," IEEE Trans. on Ind. Electron., vol. 63, no. 1, pp. 538-549, Jan. 2016.

[30] Feng Gao, P.Chiang Loh, F.Blaabjerg,"Dual Z-Source Inverter With Three-Level Reduced Common-Mode Switching", IEEE Trans. on Ind. Appl., vol. 43, no. 6, pp. 1597-1608, Nov. 2007.

[31] G.Grandi, C.Rossi, D.Ostojic, D.Casadei, "A new multilevel conversion structure for grid-connected PV applications," IEEE Trans. on Ind. Electron., vol. 56, no. 11, pp. 416-4426, 2009.

[32] S.Chowdhury, Patrick Wheeler, Chris Gerada, S. Lopez Arevalo, "A dual inverter for an open end winding induction motor drive without an isolation transformer," Conf. Proc. IEEE Applied Power Electronics Conference and Exposition, IEEE-APEC'15, Charlotte, NC, USA, pp. 283-289, 15-19 March 2015.

[33] P.Sanjeevikumar, Frede Blaabjerg, Patrick Wheeler, Olorunfemi Ojo, "Three-phase multilevel inverter configuration for open-winding high power application", Conf. Proc., The 6th IEEE Intl. Symp. on Power Electron. for Distributed Generation Systems, IEEE-PEDG'15, Aachen (Germany), 22-25 June 2015.

[34] P.Sanjeevikumar, F.Blaabjerg, Patrick Wheeler, Olorunfemi Ojo, Pandav K. Maroti, "A Novel Double Quad-Inverter Configuration for Multileve Twelve-Phase Open- Winding Converter", Conf. Proc. of 7th IEEE Intl. Conf. on Power System, IEEE-ICPS'16, Indian Institute of Technology (IIT-Delhi), Delhi (India), 4-6 Mar. 2016.

[35] P.Sanjeevikumar, F.Blaabjerg, Patrick Wheeler, Raghav Khanna, S.B. Mahajan, Sanjeet Dwivedi, "Optimized Carrier Based Five-Leve Generated Modified Dual Three-Phase Open- Winding Inverter For Medium Power Application", Conf. Prof. of IEEE International Transportation Electrification Conf. and Expo, Asia-Pacific, (IEEEITEC'16), Busan (Korea). 1-4 Jun. 2016. 